\title{
Annual Hazard Rate of Recurrence in Middle Eastern Papillary Thyroid Cancer over a Long-Term Follow-Up
}

\author{
Abdul K. Siraj ${ }^{1,+}$, Sandeep Kumar Parvathareddy ${ }^{1,+}$, Zeeshan Qadri ${ }^{1}$, Khawar Siddiqui ${ }^{2}$, \\ Saif S. Al-Sobhi ${ }^{3}$, Fouad Al-Dayel ${ }^{4}$ and Khawla S. Al-Kuraya ${ }^{1, *(D)}$ \\ 1 Human Cancer Genomic Research, Research Center, King Faisal Specialist Hospital and Research Center, \\ P.O. Box 3354, Riyadh 11211, Saudi Arabia; asiraj@kfshrc.edu.sa (A.K.S.); \\ psandeepkumar@kfshrc.edu.sa (S.K.P.); sqadri96@kfshrc.edu.sa (Z.Q.) \\ 2 Department of Pediatric Hematology-Oncology, King Faisal Specialist Hospital and Research Center, \\ P.O. Box 3354, Riyadh 11211, Saudi Arabia; ksiddiqui@kfshrc.edu.sa \\ 3 Department of Surgery, King Faisal Specialist Hospital and Research Center, \\ P.O. Box 3354, Riyadh 11211, Saudi Arabia; sobhi@kfshrc.edu.sa \\ 4 Department of Pathology, King Faisal Specialist Hospital and Research Centre, \\ P.O. Box 3354, Riyadh 11211, Saudi Arabia; dayelf@kfshrc.edu.sa \\ * Correspondence: kkuraya@kfshrc.edu.sa; Tel.: +966-1-205-5167 \\ $\dagger$ These authors contributed equally to this work.
}

Received: 29 October 2020; Accepted: 2 December 2020; Published: 3 December 2020

Simple Summary: Tumor recurrence is a relatively common event in papillary thyroid cancer (PTC). The aim of this study was to analyze the time-varying pattern of recurrence in PTC using annual hazard function and establish a predictive model for early and late recurrences. We found a double-peaked pattern of annual hazard of recurrence, with the risk being highest during the first 5 years after surgery. We also found distinct clinico-pathological parameters that could independently predict the occurrence of early recurrence (first 5 years) as compared to late recurrence (after 5 years). Overall, this study highlights the importance of long-term follow-up of PTC patients. Furthermore, the findings of our study could help in establishing individualized treatment and surveillance plans in PTC patients.

\begin{abstract}
Predicting the pattern of recurrence in papillary thyroid cancer (PTC) is necessary to establish optimal surveillance and treatment strategies. We analyzed changes in hazard rate (HR) for tumor recurrence over time in 1201 unselected Middle Eastern PTC patients. The changes in risk were further analyzed according to clinical variables predictive of early ( $\leq 5$ years) and late ( $>5$ years) recurrence using Cox regression analysis to identify patient populations that remain at risk. Tumor recurrence was noted in $18.4 \%$ (221/1201) patients. The annualized hazard of PTC recurrence was highest during the first 5 years $(2.8 \%)$, peaking between 1 and 2 years $(3.7 \%)$, with a second smaller peak between 13 and 14 years (3.2\%). Patients receiving radioactive iodine (RAI) therapy had lower recurrence hazard compared to those who did not $(1.5 \%$ vs. $2.7 \%, p=0.0001)$. Importantly, this difference was significant even in intermediate-risk PTC patients $(0.7 \%$ vs. $2.3 \% ; p=0.0001)$. Interestingly, patients aged $\geq 55$ years and having lymph node metastasis were at persistent risk for late recurrence. In conclusion, we confirmed the validity of the double-peaked time-varying pattern for recurrence risk in Middle Eastern PTC patients and our findings could help in formulating individualized treatment and surveillance plans.
\end{abstract}

Keywords: annual hazard; recurrence; time-varying; papillary thyroid cancer; radioactive iodine 


\section{Introduction}

Thyroid cancer is the most common endocrine cancer, and its incidence is increasing worldwide [1,2]. Nearly $20 \%$ of papillary thyroid cancer (PTC) patients who have no evidence of disease after initial treatment present with recurrence of disease during subsequent follow-up [3-6]. Although most recurrences in PTC are not fatal, they can be a great burden for patients, especially in a population with a high incidence rate for PTC, like Saudi Arabia [7].

The timing of recurrence in PTC varies considerably, being influenced by classical prognostic factors and adjuvant radioactive iodine (RAI) treatment strategies [8-11]. The average time to recurrence has been reported in the literature as being anywhere from 6 months to decades later [12-14]. However, it is only recently that clinical studies have begun to lay emphasis on late relapse in PTCs, with very little being known regarding the pattern of recurrence occurring beyond 10 years of follow-up [15]. Furthermore, most of the studies analyzing long-term outcomes in PTC have often focused on mortality rather than recurrence [16,17]. However, survival in PTCs is usually excellent and hence less informative about the natural history of disease after long-term follow-up [18-20]. The American Thyroid Association (ATA), in 2015, announced new treatment guidelines for differentiated thyroid cancer based on risk of recurrence [21]. Utilization of the ATA risk stratification has allowed for a more individualized approach to patient treatment [22-25]. Thus, it is important to understand changes in the risk of recurrence over time and to assess how clinical factors affect these changes. A better description of recurrence patterns, leading to a greater understanding of time-specific risk, could result in a more tailored therapeutic approach.

The purpose of this study was to analyze the hazard of recurrence after surgery for PTC patients from this ethnicity, where the prevalence of PTC is high in comparison to other populations, and to clarify the changes in hazard rate for recurrence over time in PTC patients. We also estimated the hazard rate of recurrence in RAI ablation patients from the entire cohort and with reference to the ATA risk categories. Finally, the risk factors for early and late recurrence were explored, offering unique opportunities to better define patterns of PTC recurrence.

\section{Results}

A total of 1201 patients were included in the analysis. Clinico-pathological characteristics of the study population are summarized in Table 1. Tumor recurrence was noted in 18.4\% (221/1201) patients. The majority of the patients had regional recurrence $(115 / 221 ; 52.0 \%)$. Distant metastasis was seen in $29.9 \%(66 / 221)$ cases, involving the lungs (50 cases; $75.8 \%)$, bone ( 9 case; $13.7 \%)$, both the lungs and bone ( 5 cases; $7.5 \%$ ), brain (1 cases; $1.5 \%$ ) and both lung and liver (1 case; $1.5 \%$ ). Local recurrence was identified in $18.1 \%$ (40/221) cases, with $70 \%$ (28/40) of them occurring in the operated thyroid bed and the remaining 30\% (12/40) in the residual thyroid tissue. Moreover, 87.3\% (193/221) of recurrences occurred within the first 10 years after initial treatment, with the majority occurring within the first five years (144 cases; $65.2 \%$ ), whereas $12.7 \%$ (28/221) of cases occurred between 10 and 20 years after surgery.

Table 1. Clinico-pathological variables for the patient cohort $(n=1201)$.

\begin{tabular}{cc}
\hline Clionico-Pathological Variables & $\boldsymbol{n}(\%)$ \\
\hline Age at surgery (years) & \\
$<55$ & $979(81.5)$ \\
$\geq 55$ & $222(18.5)$ \\
\hline Gender & \\
Male & $289(24.1)$ \\
Female & $912(75.9)$ \\
\hline Histologic subtype & \\
Classical variant & $815(67.9)$ \\
Follicular variant & $248(20.6)$ \\
Tall cell variant & $114(9.5)$ \\
Other variants & $24(2.0)$ \\
\hline
\end{tabular}


Table 1. Cont.

\begin{tabular}{|c|c|}
\hline Clionico-Pathological Variables & $n(\%)$ \\
\hline \multicolumn{2}{|l|}{ Histologic subtype } \\
\hline Aggressive variants & $138(11.5)$ \\
\hline Non-aggressive variants & $1063(88.5)$ \\
\hline \multicolumn{2}{|l|}{ Tumor size $(\mathrm{cm})$} \\
\hline$\leq 4$ & $601(50.8)$ \\
\hline$>4$ & $582(49.2)$ \\
\hline \multicolumn{2}{|l|}{ Multifocality } \\
\hline Yes & $599(49.9)$ \\
\hline No & $602(50.1)$ \\
\hline \multicolumn{2}{|l|}{ Extrathyroidal extension } \\
\hline ExT0 & $700(58.3)$ \\
\hline ExT1 & $411(34.2)$ \\
\hline ExT2 & $90(7.5)$ \\
\hline \multicolumn{2}{|l|}{ Number of lymph nodes involved } \\
\hline$\leq 5$ & $913(80.3)$ \\
\hline$>5$ & $224(19.7)$ \\
\hline \multicolumn{2}{|l|}{ Lymph node metastasis } \\
\hline No & $565(47.1)$ \\
\hline N1a & $165(13.7)$ \\
\hline $\mathrm{N} 1 \mathrm{~b}$ & $407(33.9)$ \\
\hline $\mathrm{Nx}$ & $64(5.3)$ \\
\hline \multicolumn{2}{|l|}{ Extent of thyroidectomy } \\
\hline Total thyroidectomy & $1030(85.8)$ \\
\hline Less than total thyroidectomy & $171(14.2)$ \\
\hline \multicolumn{2}{|l|}{ Risk class } \\
\hline Low & $183(15.2)$ \\
\hline Intermediate & $430(35.8)$ \\
\hline High & $588(49.0)$ \\
\hline \multicolumn{2}{|l|}{ Recurrence } \\
\hline Yes & $221(18.4)$ \\
\hline Local & $40(3.3)$ \\
\hline Regional & $115(9.6)$ \\
\hline Distant & $66(5.5)$ \\
\hline No & $980(81.6)$ \\
\hline \multicolumn{2}{|l|}{ TNM stage } \\
\hline I & 957 (79.7) \\
\hline II & $160(13.3)$ \\
\hline III & $63(5.2)$ \\
\hline IV & $21(1.8)$ \\
\hline \multicolumn{2}{|l|}{ Radioactive iodine therapy } \\
\hline Yes & $937(78.0)$ \\
\hline No & $264(22.0)$ \\
\hline \multicolumn{2}{|l|}{ Status at last follow-up } \\
\hline Alive & $1162(96.8)$ \\
\hline Deceased & $39(3.2)$ \\
\hline Due to Papillary thyroid cancer & $25(2.1)$ \\
\hline Due to other reasons & $14(1.1)$ \\
\hline \multicolumn{2}{|l|}{ BRAF mutation } \\
\hline Present & $675(56.2)$ \\
\hline Absent & $470(39.1)$ \\
\hline Unknown & $56(4.7)$ \\
\hline
\end{tabular}


Table 1. Cont.

\begin{tabular}{cc}
\hline Clionico-Pathological Variables & $\boldsymbol{n} \mathbf{( \% )}$ \\
\hline NRAS mutation & \\
Present & $77(6.4)$ \\
Absent & $1063(88.5)$ \\
Unknown & $61(5.1)$ \\
\hline HRAS mutation & \\
Present & $22(1.8)$ \\
Absent & $1115(92.9)$ \\
Unknown & $64(5.3)$ \\
\hline Follow-up duration (years) & \\
Median & 9.50 \\
Range & $0.01-30.01$ \\
\hline Clinico-pathologial variables are highlighted in bold.
\end{tabular}

\subsection{Recurrence Hazard Analysis in the Entire Cohort}

The annual hazard curve of recurrence for the entire study population showed a double-peaked pattern, with peaks at 1-2 and 13-14 years after initial treatment (Figure 1A). The annualized hazard of PTC recurrence was highest during the first 5 years $(2.8 \%)$, peaking at 2 years $(3.7 \%)$. The hazard decreased to $1.8 \%$ between 5 and 10 years but increased again between 10 and 15 years (2.4\%) (Table 2). When stratified based on ATA risk categories, the curves exhibited a double-peaked pattern in highand intermediate-risk patients, but not in the low-risk patients, where it showed a single-peak pattern of recurrence. The recurrence peak emerged earlier for high- and intermediate-risk patients compared to the peak for low-risk patients, suggesting that low-risk PTC patients were less likely to recur early (Figure 1B).

Smoothed Hazard rate: Any recurrence

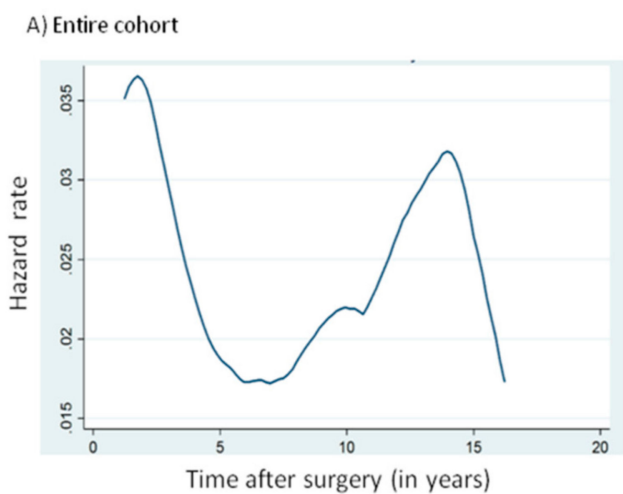

B) Risk classes

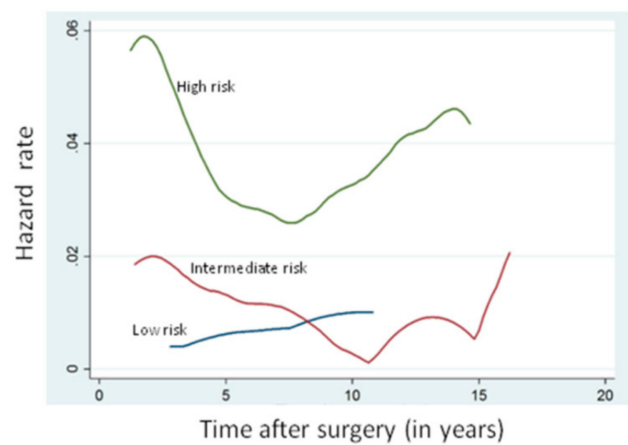

Figure 1. Annual hazard rate of cancer recurrence for the (A) entire population and (B) different risk classes.

Table 2. Annual hazard of recurrence estimated within 5-year intervals in the entire cohort and different risk classes.

\begin{tabular}{|c|c|c|c|c|c|}
\hline \multirow{2}{*}{ Outcome } & \multicolumn{4}{|c|}{ Hazard $(\% ;$ SE) } & \multirow{2}{*}{$p$ Value } \\
\hline & Years 0-5 & Years 5-10 & Years 10-15 & Years 15-20 & \\
\hline \multicolumn{6}{|l|}{ RFS } \\
\hline All patients & $2.8(0.2)$ & $1.8(0.3)$ & $2.4(0.5)$ & $1.1(0.5)$ & $0.021 *$ \\
\hline Low Risk & $0.2(0.2)$ & $1.0(0.4)$ & $0.5(0.5)$ & $0.0(0.0)$ & 0.354 \\
\hline Intermediate Risk & $1.8(0.3)$ & $0.9(0.3)$ & $0.4(0.4)$ & $1.4(1.4)$ & 0.177 \\
\hline High Risk & $4.6(0.4)$ & $2.8(0.5)$ & $3.9(0.8)$ & $1.4(0.8)$ & $0.003 *$ \\
\hline
\end{tabular}

RFS-Recurrence-free survival; *, significant $p$ value. 
2.2. Recurrence Hazard Analysis Based on RAI Status.

Since the majority $(78.0 \%$; 937/1201, Table 1$)$ of cases in our cohort received RAI therapy following initial surgery, we analyzed the annual hazard of recurrence based on the RAI therapy status. Throughout the follow-up period, patients receiving RAI therapy had a lower hazard of recurrence compared to those who did not receive RAI therapy ( $1.5 \%$ vs. $2.7 \%, p=0.0001)$ (Table 3, Figure 2). On analyzing the annualized hazard of recurrence in 5-year intervals, difference was significantly lower in the RAI treated group compared to RAI untreated group between years 0 and $5(2.2 \% \mathrm{vs} .5 .7 \%$; $p=0.0001)$ and 10 and $15(2.0 \%$ vs. $6.0 \% ; p=0.0232)$, whereas it was not significant between years 5 and $10(1.7 \%$ vs. $2.6 \% ; p=0.2544)$ and 15 and $20(0.9 \%$ vs. $2.5 \% ; p=0.4307)$ (Table 4$)$. A similarly significant difference in recurrence over time was noted for high- and intermediate-risk but not low-risk patients (Table 4).

Table 3. Annual hazard of recurrence in the entire cohort and in different risk categories with respect to radioactive iodine (RAI) ablation status.

\begin{tabular}{cccc}
\hline Groups & RAI Status & Annual Hazard (\%; SE) & p Value \\
\hline \multirow{2}{*}{ Entire cohort } & RAI given & $1.5(0.1)$ & \multirow{2}{*}{$0.0001^{*}$} \\
\cline { 2 - 3 } & RAI not given & $2.7(0.3)$ & \multirow{2}{*}{$0.0001^{*}$} \\
\cline { 2 - 3 } High risk & RAI given & $2.9(0.3)$ & \multirow{2}{*}{$0.0001^{*}$} \\
\cline { 2 - 3 } Intermediate risk & RAI not given & $5.8(0.8)$ & \multirow{2}{*}{0.8427} \\
\cline { 2 - 3 } & RAI given & $2.3(0.5)$ & \\
\hline \multirow{2}{*}{ Low risk } & RAI not given & $0.4(0.2)$ & $0.5(0.3)$ \\
\hline
\end{tabular}

*, significant $p$ value.

\section{Smoothed Hazard rate: Any recurrence}

RAl + vs. RAI -

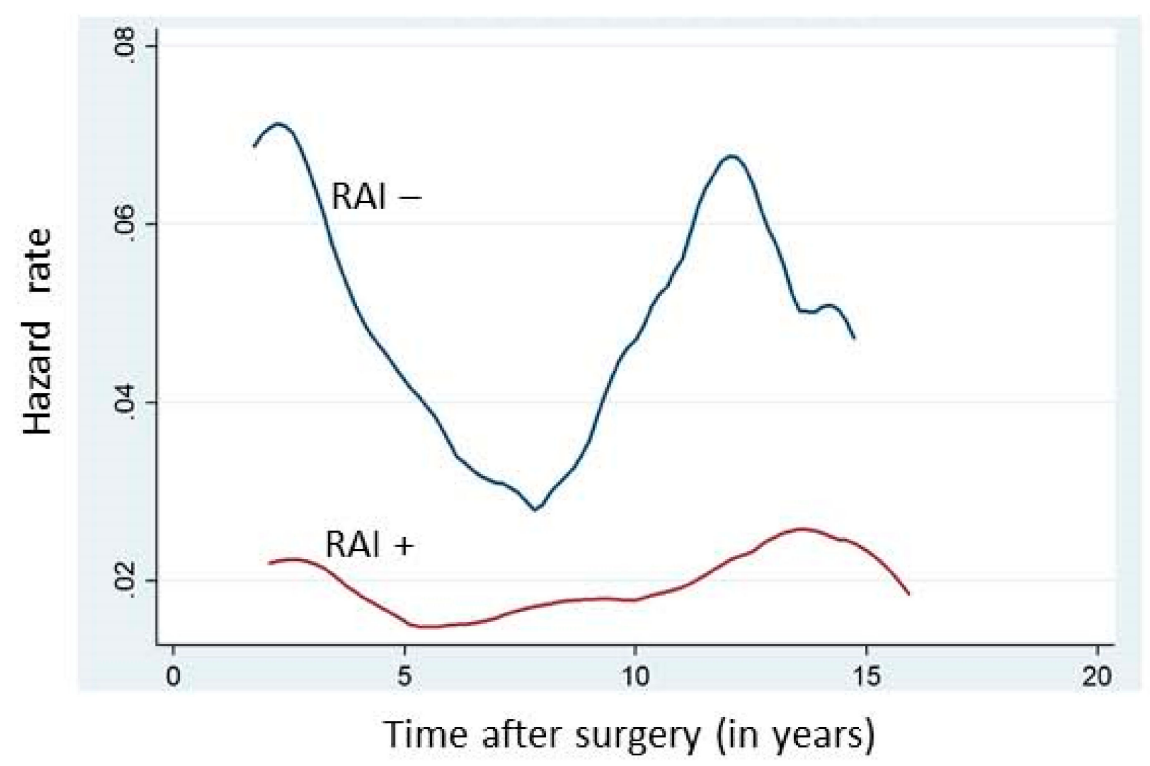

Figure 2. Annual hazard rate of cancer recurrence in the entire cohort according to RAI status. 
Table 4. Annual hazard of recurrence estimated within 5-year intervals based on RAI ablation status in the overall cohort and different risk categories.

\begin{tabular}{ccccc}
\hline \multirow{2}{*}{ Outcome } & \multicolumn{3}{c}{ Hazard (\%; SE) } \\
\cline { 2 - 4 } & Years 0-5 & Years 5-10 & Years 10-15 & Years 15-20 \\
\hline RFS (Overall cohort) & & & & \\
RAI + & $2.2(0.2)$ & $1.7(0.3)$ & $2.0(0.5)$ & $0.9(0.5)$ \\
RAI - & $5.7(0.8)$ & $2.6(0.8)$ & $6.0(2.2)$ & $2.5(2.5)$ \\
$p$ value & $0.0001^{*}$ & 0.2544 & $0.0232^{*}$ & 0.4307 \\
RFS (High risk) & & & & $0.7(0.7)$ \\
RAI + & $3.6(0.4)$ & $2.5(0.5)$ & $3.2(0.8)$ & $40.0(0.0)$ \\
RAI - & $10.5(1.7)$ & $6.0(2.4)$ & $20.0(7.8)$ & NA \\
$p$ value & $0.0001^{*}$ & $0.0229 *$ & $0.0001^{*}$ & $1.7(1.7)$ \\
RAI + & $1.1(0.3)$ & $0.7(0.3)$ & $0.0(0.0)$ & $0.0(0.0)$ \\
RAI - & $4.8(1.2)$ & $2.2(1.3)$ & $3.3(3.3)$ & 0.6301 \\
$p$ value & $0.0004 *$ & 0.0840 & $0.0003 *$ & $0.0(0.0)$ \\
RFS (Low risk) & & & & $0.0(0.0)$ \\
RAI + & $0.2(0.2)$ & $1.1(0.6)$ & $0.0(0.0)$ & 0.6693 \\
RAI - & $0.4(0.4)$ & $0.7(.7)$ & $1.6(1.6)$ & 0.1708 \\
$p$ value & 0.6693 & 0.6724 & &
\end{tabular}

Furthermore, since the role of RAI ablation in intermediate-risk PTC is controversial, we sought to analyze the annual hazard of recurrence with respect to RAI status in the intermediate-risk PTC. We found that patients with intermediate-risk PTC had a significantly higher hazard of recurrence in the RAI untreated group compared to the RAI treated group (2.3\% vs. $0.7 \%$; $p=0.0001)$ (Table 3 , Figure 3 ).

\section{Smoothed Hazard rate: Any recurrence in Intermediate risk PTC cases}

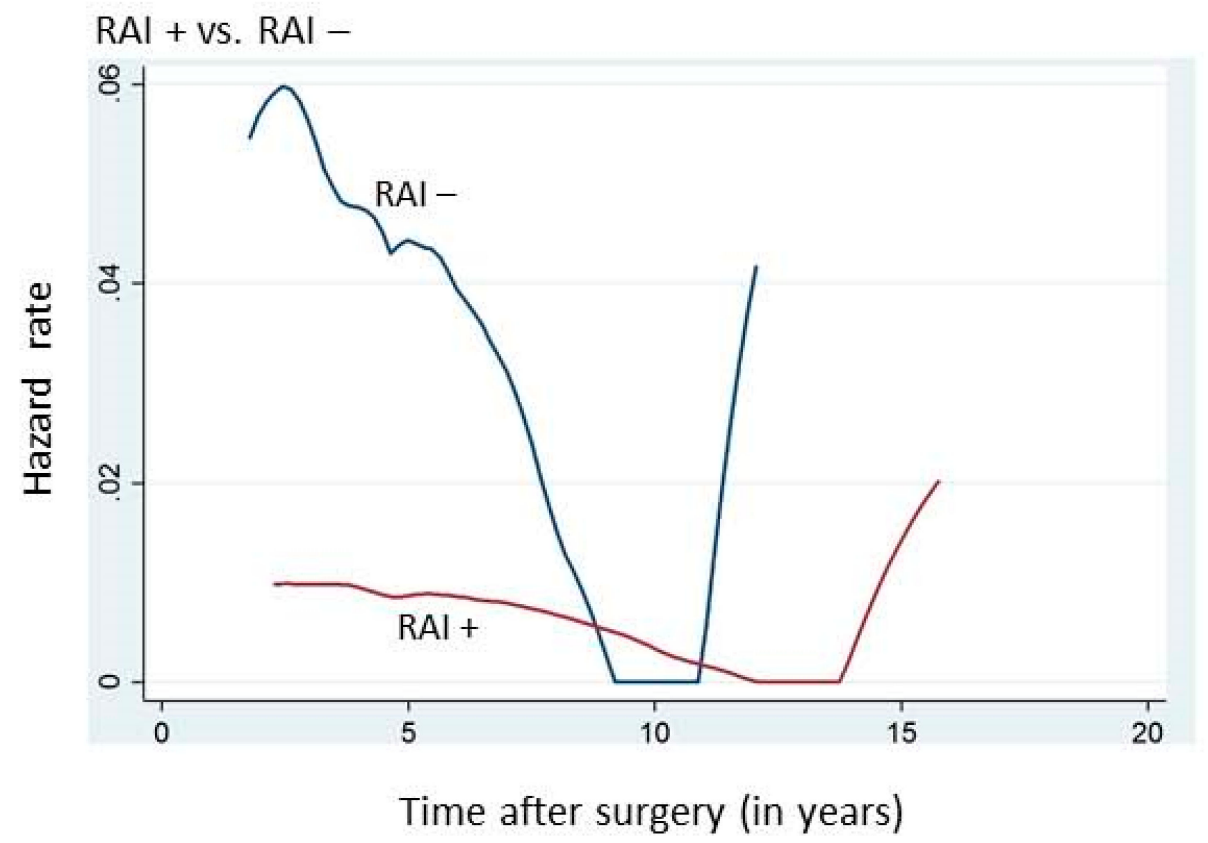

Figure 3. Annual hazard rate of cancer recurrence in the intermediate risk PTC according to RAI status.

\subsection{Factors Predicting Early and Late Recurrence of PTC on Multivariate Analysis}

Figure 1B shows a double-peaked pattern for high- and intermediate-risk patients, whereas Table 4 shows a significant difference in the recurrence rate over time for high- and intermediate-risk patients 
but not low-risk patients. Hence, we restricted the multivariate analysis using Cox regression to only high- and intermediate-risk patients. Since the first peak for both high- and intermediate-risk patients plateaued at around 5 years, we divided the recurrences into early ( $0-5$ years) and late ( $>5$ years) in order to analyze the factors that could predict these early and late recurrence. On Cox regression model analysis, male gender, age $\geq 55$ years, T3-4 tumors and lymph node metastasis were predictors of early tumor recurrence in PTC (Table 5). Only age $\geq 55$ years and lymph node metastasis were predictors of late tumor recurrence in PTC (Table 6).

Table 5. Cox regression model analysis for prediction of early tumor recurrence ( $0-5$ years).

\begin{tabular}{cccccc}
\hline Variables & Characteristic & Estimate (SE) & Hazard Ratio & 95\% CI & $p$ Value \\
\hline Gender & Male (vs. Female) & $-0.424(0.190)$ & 0.654 & $0.451-0.949$ & $0.025^{*}$ \\
Age & $\geq 55$ years (vs. <55 years) & $0.798(0.212)$ & 2.222 & $1.465-3.369$ & $<0.001^{*}$ \\
Tumor size & T3-4 (vs. T1-2) & $0.796(0.264)$ & 2.216 & $1.320-3.720$ & $0.003^{*}$ \\
Lymph node & N1 (vs. N0) & $0.875(0.218)$ & 2.399 & $1.565-3.676$ & $<0.001^{*}$ \\
metastasis & Yes (vs. No) & $-0.148(0.186)$ & 0.863 & $0.599-1.242$ & 0.296 \\
Multifocality & Microscopic (vs. absent) & $0.276(0.261)$ & 1.317 & $0.791-2.195$ & 0.290 \\
Extra-thyroidal & Gross (vs. absent) & $0.522(0.408)$ & 1.685 & $0.758-3.764$ & 0.201 \\
extension & Aggressive & $-0.192(0.272)$ & 0.825 & $0.484-1.406$ & 0.480 \\
Histology & (vs. non-aggressive) & $0.389(0.331)$ & 1.476 & $0.772-2.822$ & 0.239 \\
Stage & III-IV (vs. I-II) & $-0.169(0.206)$ & 0.845 & $0.564-1.264$ & 0.412 \\
BRAF mutation & Present (vs. absent) & $-1.341(0.197)$ & 0.262 & $0.178-0.385$ & $<0.001 *$ \\
Radioactive iodine & Given (vs. not given) &
\end{tabular}

* Significant $p$ value.

Table 6. Cox regression model analysis for prediction of late tumor recurrence ( $>5$ years).

\begin{tabular}{cccccc}
\hline Variables & Characteristic & Estimate (SE) & Hazard Ratio & $\mathbf{9 5 \%}$ CI & $p$ Value \\
\hline Gender & Male (vs. Female) & $-0.491(0.275)$ & 0.612 & $0.357-1.049$ & 0.074 \\
Age & $\geq 55$ years (vs. <55 years) & $1.468(0.291)$ & 4.339 & $2.454-7.672$ & $<0.001^{*}$ \\
Tumor size & T3-4 (vs. T1-2) & $0.783(0.419)$ & 2.188 & $0.962-4.979$ & 0.062 \\
Lymph node & N1 (vs. N0) & $0.862(0.302)$ & 2.368 & $1.311-4.277$ & $0.004^{*}$ \\
metastasis & Yes (vs. No) & $-0.264(0.262)$ & 0.768 & $0.459-1.284$ & 0.314 \\
Multifocality & Microscopic (vs. absent) & $0.081(0.400)$ & 1.084 & $0.495-2.375$ & 0.841 \\
Extra-thyroidal & Gross (vs. absent) & $-0.294(0.827)$ & 0.746 & $0.147-3.773$ & 0.723 \\
extension & Aggressive & $-0.114(0.456)$ & 0.893 & $0.365-2.183$ & 0.803 \\
Histology & (vs. non-aggressive) & $1.232(0.700)$ & 3.430 & $0.870-13.512$ & 0.078 \\
Stage & III-IV (vs. I-II) & $0.561(0.333)$ & 1.753 & $0.912-3.369$ & 0.092 \\
BRAF mutation & Present (vs. absent) & $-1.391(0.328)$ & 0.249 & $0.131-0.473$ & $<0.001 *$ \\
Radioactive iodine & Given (vs. not given) & & & &
\end{tabular}

* Significant $p$ value.

\section{Discussion}

Risk analysis of tumor recurrence is highly important for the detection of recurrence, especially in PTC patients. In most of the existing studies, risk of recurrence has been analyzed by survival curves rather than using the hazard functions $[26,27]$. While survival curves only provide information on the cumulative time distribution of recurrence-free rate, hazard functions can depict the recurrence rate at any point in time among the remaining at-risk individuals [28].

In our study, the overall recurrence rate was relatively high. Although the majority (78\%) of patients had received radioactive iodine (RAI), nearly one-fifth (18.4\%) of patients suffered from disease recurrence in this study. This relatively high percentage is in concordance with other populations $[13,29,30]$. Interestingly, a recent study from a Japanese PTC cohort showed a similar recurrent rate despite only $1.5 \%$ of patients receiving RAI therapy [15]. The relatively high incidence of recurrence in this cohort could be due to the uniqueness of PTC in this population in that nearly 
$50 \%$ of patients presented with high-risk disease and only $15 \%$ had low-risk disease, which is not seen in most modern studies of western populations and could be attributed to genetics or differences in presentation and access to healthcare. Another reason for the high incidence of recurrence could be due to referral bias since patients with advanced disease are referred to our hospital from all over Saudi Arabia. Previous studies from Saudi Arabia have also reported a higher incidence of advanced disease [31,32], suggesting that thyroid cancer from Saudi Arabia could be more aggressive than in other parts of the world.

The annual hazard curve of recurrence for the entire cohort showed a double-peaked pattern, with the first major surge reaching a peak during the second year after surgery, followed by another peak between 13 and 14 years. The annual hazard curves exhibited double-peaked distribution for highand intermediate-risk patients and single-peaked distribution for low-risk patients. The recurrence peak for high- and intermediate-risk patients emerged earlier than low-risk patients, which suggests the importance of high surveillance and follow-up to detect early recurrence in this subset of patients. Furthermore, since low-risk PTC patients had a very low hazard of recurrence beyond 10 years of initial surgery, long-term follow-up may not be necessary for this group of patients. The double-peaked pattern of recurrence hazard in our study is in line with the tumor dormancy theory [33,34], which hypothesizes that micro-metastatic foci may exist in varying biological steady states, with most of them remaining dormant. However, this steady state may be disrupted by surgery, stimulating the switch from dormancy to growth, hence causing a sudden acceleration of metastatic process resulting in recurrence [35].

This double-peaked recurrence hazard pattern has been previously observed in several cancers [36-39]. Despite limited studies on the hazard of recurrence in thyroid cancer, a recent study by Dong et al. [15] in a cohort of 400 Japanese PTC patients showed triple-peaked annual hazard of recurrence with surges at 12, 22 and 29 years after initial surgery. Several factors might contribute to the difference in annual hazard curves between our study and Dong's study. Sample size, follow-up timing, risk stratification, adjuvant RAI therapy given and ethnic differences might help in explaining these differences.

Little is known about the hazard of recurrence with respect to RAI status. Our data showed that patients receiving RAI therapy had a significantly reduced annual hazard of recurrence compared to those who did not receive RAI, particularly in high- and intermediate-risk patients $(p=0.0001)$. This highlights the clinical importance of giving RAI in intermediate-risk PTC patients. Giving RAI in intermediate-risk PTC has been a subject of controversy. On the one hand, studies have shown that RAI therapy could reduce recurrence and hence should be considered in intermediate-risk PTC patients [21,40], whereas others have suggested that RAI ablation may not have a beneficial role in decreasing the risk of recurrence in intermediate-risk PTC patients [41,42].

The present study is unique in that it explored the risk factors that could predict early and late recurrence using Cox regression analysis. This analysis revealed that PTC patients who were male, aged $\geq 55$ years, with T3-4 tumors and lymph node metastasis were at high risk for early recurrence, whereas only age and lymph node metastasis were predictors of late recurrence. Our data suggest that a subset of patients who are male with T3-4 tumors might need more intensive surveillance in the initial 5 years following surgery, whereas those patients who are aged $\geq 55$ years and have lymph node metastasis will have to be followed up for a longer period of time.

\section{Materials and Methods}

\subsection{Patient Selection}

One thousand four-hundred and sixty-six consecutive unselected PTC patients diagnosed between 1988 and 2015 at King Faisal Specialist Hospital and Research Centre (Riyadh, Saudi Arabia) were available to be included in the study. Cases were identified based on clinical history followed by fine needle aspiration cytology for confirmation. However, patients aged $\leq 18$ years $(n=84)$, with a history of previous thyroidectomy $(n=144)$ or who were never free of disease $(n=37)$ were excluded from 
the study. After exclusion, 1201 patients were eligible and included in this study. The Institutional Review Board of the hospital approved this study and the Research Advisory Council (RAC) provided waiver of consent under project RAC \# 2110031.

\subsection{Clinico-Pathological Data}

The baseline clinico-pathological data were collected from case records and have been summarized in Table 1. Extra-thyroidal extension was further classified as follows: ExT0, no extra-thyroidal extension; ExT1 (microscopic extra-thyroidal extension), microscopic invasion of tumor into perithyroidal soft tissues; ExT2 (gross extra-thyroidal extension), macroscopic invasion of tumor into perithyroidal soft tissues. Staging of PTC was performed using the eighth edition of American Joint Committee on Cancer (AJCC) staging system. Patients were stratified into low, intermediate and high risk based on 2015 ATA guidelines [21]. Thyroidectomies were divided into either total thyroidectomy or less than total thyroidectomy (subtotal, lobectomy). Overall, 78.0\% (937/1201) of patients received radioactive iodine therapy following surgery. Low-risk patients received a mean cumulative RAI dosage of $110.2 \mathrm{mCi}(\mathrm{SD}= \pm 44.6 \mathrm{mCi}$ ), intermediate-risk patients received $135.6 \pm 74.8 \mathrm{mCi}$ and high-risk patients received $187.8 \pm 136.4 \mathrm{mCi}$. Based on the ATA guidelines, tall cell, hobnail, columnar cell, diffuse sclerosing and insular variants were classified as aggressive variants, whereas classical and follicular variants were classified as non-aggressive variants.

\subsection{Classification of Recurrence}

Recurrence was defined as any newly detected tumor or metastatic lymph node based on ultrasound and/or imaging studies in patients who had been previously free of disease following initial treatment. Recurrence was classified according to the site, as follows: "local recurrence" if only the residual thyroid gland tissue or thyroid bed was involved; "regional recurrence" if central or lateral neck lymph nodes were involved; "distant recurrence" if disease was seen in soft tissues or lymph nodes at distant sites and visceral metastasis in other organs such as the lungs, liver, bones and brain. Biochemical recurrences were not considered for this study.

\subsection{Follow-Up and Study Endpoints}

Following initial surgery, low-risk PTC patients were followed up annually, intermediate-risk patients were followed up at 6-month intervals and high-risk patients were followed up at 3-month intervals. At each follow-up, neck ultrasound, thyroid function tests, thyroglobulin levels and thyroglobulin antibodies were performed. In addition, for high-risk patients, radioiodine scan and PET CT scan were performed at each follow-up to identify tumor recurrence. A biopsy confirmation (fine needle aspiration or histopathology) of tumor recurrence was obtained in $51.1 \%(113 / 221)$ cases. The remaining $48.9 \%$ (108/221) of cases were diagnosed by imaging studies alone. The median follow-up was 9.5 years (range 0.02-30.01 years). The primary study endpoint for our analysis was recurrence-free survival (RFS). RFS was defined as the time (in years) from date of initial surgery to the occurrence of any tumor recurrence (local, regional or distant). In the case of no recurrence, date of last follow-up was the study endpoint.

\subsection{DNA Isolation and Sanger Sequencing Analysis}

DNA samples were extracted from formalin-fixed and paraffin-embedded (FFPE) PTC tumor tissues utilizing Gentra DNA Isolation Kit (Gentra, Minneapolis, MN, USA) according to the manufacturer's protocols, as elaborated in previous studies [43].

Sequencing of entire coding and splicing regions of exon 15 in BRAF gene, exon 2 and 3 in HRAS and NRAS genes among 1201 PTC samples was carried out using Sanger sequencing technology. Primer 3 online software was utilized to design the primers (available upon request, Primer3web v4.1.0, https://primer3.ut.ee/). PCR and Sanger sequencing analysis were carried out as described previously [44]. Reference sequences were downloaded from the NCBI GenBank and sequencing 
results were compared with the reference sequences by Mutation Surveyor V4.04 (Soft Genetics, LLC, State College, PA, USA).

\subsection{Statistical Analysis}

Annual hazard rates were estimated using the maximum likelihood estimate from piece-wise exponential model and Kernel smoothing method was used for graphical representation. To determine the independent prognostic factors for early and late recurrence, Cox proportional hazards regression model was used. Covariates for Cox regression analysis were selected if they were statistically significant on univariate analysis. All the variables were significant on univariate analysis, except for multifocality and histology. However, these two variables were included since they are integral to the ATA risk stratification of PTCs. Two-sided tests were used for statistical analyses, with a limit of significance defined as $p$ value $<0.05$. Statistical analyses were performed using Stata v9.0 (StataCorp Ltd., College Station, TX, USA) and SPSS v20.0 (SPSS, Chicago, IL, USA).

\section{Conclusions}

This study confirms the validity of double-peaked time-varying pattern for risk of recurrence in Middle Eastern PTC patients. We therefore provide further support to the tumor dormancy hypothesis reported by Demicheli et al. [34]. Furthermore, according to the time distribution of recurrence hazard, we could formulate individualized treatment and surveillance plans in PTC patients.

Author Contributions: Conceptualization, K.S.A.-K.; Methodology, A.K.S. and S.K.P.; Software, Z.Q., K.S.; Validation, S.K.P. and Z.Q., K.S.; Formal Analysis, A.K.S., S.K.P. and Z.Q., K.S.; Investigation, S.K.P., Z.Q., K.S., S.S.A.-S. and F.A.-D.; Resources, S.K.P., S.S.A.-S. and F.A.-D.; Data Curation, A.K.S., S.K.P. and Z.Q.; Writing-Original Draft Preparation, K.S.A.-K.; Writing-Review and Editing, A.K.S., S.K.P. and K.S.A.-K.; Visualization, S.K.P. and Z.Q.; Supervision, K.S.A.-K. and A.K.S.; Project Administration, K.S.A.-K. and A.K.S.; Funding Acquisition, K.S.A.-K.; reviewed and approved text: all authors. All authors have read and agreed to the published version of the manuscript.

Funding: This research received no external funding.

Acknowledgments: The authors thank Felisa DeVera and Padmanaban Annaiyappanaidu for their technical assistance.

Conflicts of Interest: The authors declare no conflict of interest.

\section{References}

1. Bray, F.; Ferlay, J.; Soerjomataram, I.; Siegel, R.L.; Torre, L.A.; Jemal, A. Global cancer statistics 2018: GLOBOCAN estimates of incidence and mortality worldwide for 36 cancers in 185 countries. CA Cancer J. Clin. 2018, 68, 394-424. [CrossRef] [PubMed]

2. La Vecchia, C.; Malvezzi, M.; Bosetti, C.; Garavello, W.; Bertuccio, P.; Levi, F.; Negri, E. Thyroid cancer mortality and incidence: A global overview. Int. J. Cancer 2015, 136, 2187-2195. [CrossRef] [PubMed]

3. Xing, M.; Alzahrani, A.S.; Carson, K.A.; Shong, Y.K.; Kim, T.Y.; Viola, D.; Elisei, R.; Bendlová, B.; Yip, L.; Mian, C. Association between BRAF V600E mutation and recurrence of papillary thyroid cancer. J. Clin. Oncol. 2015, 33, 42. [CrossRef] [PubMed]

4. Xing, M.; Liu, R.; Liu, X.; Murugan, A.K.; Zhu, G.; Zeiger, M.A.; Pai, S.; Bishop, J. BRAF V600E and TERT promoter mutations cooperatively identify the most aggressive papillary thyroid cancer with highest recurrence. J. Clin. Oncol. 2014, 32, 2718. [CrossRef] [PubMed]

5. Nixon, I.J.; Ganly, I.; Patel, S.G.; Palmer, F.L.; Di Lorenzo, M.M.; Grewal, R.K.; Larson, S.M.; Tuttle, R.M.; Shaha, A.; Shah, J.P. The results of selective use of radioactive iodine on survival and on recurrence in the management of papillary thyroid cancer, based on Memorial Sloan-Kettering Cancer Center risk group stratification. Thyroid 2013, 23, 683-694. [CrossRef]

6. Ritter, A.; Mizrachi, A.; Bachar, G.; Vainer, I.; Shimon, I.; Hirsch, D.; Diker-Cohen, T.; Duskin-Bitan, H.; Robenshtok, E. Detecting recurrence following lobectomy for thyroid cancer: Role of thyroglobulin and thyroglobulin antibodies. J. Clin. Endocrinol. Metab. 2020, 105, dgaa152. [CrossRef] 
7. Alrawaji, A.; Alshahrani, Z.; Alzahrani, W.; Alomran, F.; Almadouj, A.; Alshehri, S.; Alzahrani, A.; Bazarbashi, S.; Alhashmi, H.; Almutlaq, H.; et al. Cancer Incidence Report Saudi Arabia 2015. In Saudi Cancer Registry; Council, S.H., Ed.; Saudi Health Council: Riyadh, Saudi Arabia, 2018.

8. Medas, F.; Canu, G.L.; Boi, F.; Lai, M.L.; Erdas, E.; Calò, P.G. Predictive Factors of Recurrence in Patients with Differentiated Thyroid Carcinoma: A Retrospective Analysis on 579 Patients. Cancers 2019, 11, 1230. [CrossRef]

9. Lee, S.H.; Roh, J.-L.; Gong, G.; Cho, K.-J.; Choi, S.-H.; Nam, S.Y.; Kim, S.Y. Risk factors for recurrence after treatment of N1b papillary thyroid carcinoma. Ann. Surg. 2019, 269, 966-971. [CrossRef]

10. Hirsch, D.; Gorshtein, A.; Robenshtok, E.; Masri-Iraqi,H.; Akirov, A.; Duskin Bitan, H.; Shimon, I.; Benbassat, C. Second radioiodine treatment: Limited benefit for differentiated thyroid cancer with locoregional persistent disease. J. Clin. Endocrinol. Metab. 2018, 103, 469-476. [CrossRef]

11. Piccardo, A.; Puntoni, M.; Bottoni, G.; Treglia, G.; Foppiani, L.; Bertoli, M.; Catrambone, U.; Arlandini, A.; Dib, B.; Altrinetti, V. Differentiated thyroid cancer lymph-node relapse. Role of adjuvant radioactive iodine therapy after lymphadenectomy. Eur. J. Nucl. Med. Mol. Imaging 2017, 44, 926-934. [CrossRef]

12. Durante, C.; Montesano, T.; Torlontano, M.; Attard, M.; Monzani, F.; Tumino, S.; Costante, G.; Meringolo, D.; Bruno, R.; Trulli, F. Papillary thyroid cancer: Time course of recurrences during postsurgery surveillance. J. Clin. Endocrinol. Metab. 2013, 98, 636-642. [CrossRef] [PubMed]

13. Grogan, R.H.; Kaplan, S.P.; Cao, H.; Weiss, R.E.; DeGroot, L.J.; Simon, C.A.; Embia, O.M.; Angelos, P.; Kaplan, E.L.; Schechter, R.B. A study of recurrence and death from papillary thyroid cancer with 27 years of median follow-up. Surgery 2013, 154, 1436-1447. [CrossRef] [PubMed]

14. Brassard, M.; Borget, I.; Edet-Sanson, A.; Giraudet, A.-L.; Mundler, O.; Toubeau, M.; Bonichon, F.; Borson-Chazot, F.; Leenhardt, L.; Schvartz, C. Long-term follow-up of patients with papillary and follicular thyroid cancer: A prospective study on 715 patients. J. Clin. Endocrinol. Metab. 2011, 96, 1352-1359. [CrossRef] [PubMed]

15. Dong, W.; Horiuchi, K.; Tokumitsu, H.; Sakamoto, A.; Noguchi, E.; Ueda, Y.; Okamoto, T. Time-varying pattern of mortality and recurrence from papillary thyroid cancer: Lessons from a long-term follow-up. Thyroid 2019, 29, 802-808. [CrossRef] [PubMed]

16. Ito, Y.; Miyauchi, A.; Kihara, M.; Fukushima, M.; Higashiyama, T.; Miya, A. Overall survival of papillary thyroid carcinoma patients: A single-institution long-term follow-up of 5897 patients. World J. Surg. 2018, 42, 615-622. [CrossRef] [PubMed]

17. Lin, J.-D.; Hsueh, C.; Chao, T.-C. Long-term follow-up of the therapeutic outcomes for papillary thyroid carcinoma with distant metastasis. Medicine 2015, 94, e1063. [CrossRef]

18. Lim, H.; Devesa, S.S.; Sosa, J.A.; Check, D.; Kitahara, C.M. Trends in thyroid cancer incidence and mortality in the United States, 1974-2013. JAMA 2017, 317, 1338-1348. [CrossRef]

19. Xing, M.; Alzahrani, A.S.; Carson, K.A.; Viola, D.; Elisei, R.; Bendlova, B.; Yip, L.; Mian, C.; Vianello, F.; Tuttle, R.M. Association between BRAF V600E mutation and mortality in patients with papillary thyroid cancer. JAMA 2013, 309, 1493-1501. [CrossRef]

20. Howlader, N.; Noone, A.M.; Krapcho, M.; Garshell, J.; Miller, D.; Altekruse, S.F.; Kosary, C.L.; Yu, M.; Ruhl, J.; Tatalovich, Z.; et al. (Eds.) SEER Cancer Statistics Review, 1975-2012; National Cancer Institute: Bethesda, MD, USA, 2015.

21. Haugen, B.R.; Alexander, E.K.; Bible, K.C.; Doherty, G.M.; Mandel, S.J.; Nikiforov, Y.E.; Pacini, F.; Randolph, G.W.; Sawka, A.M.; Schlumberger, M. 2015 American Thyroid Association management guidelines for adult patients with thyroid nodules and differentiated thyroid cancer: The American Thyroid Association guidelines task force on thyroid nodules and differentiated thyroid cancer. Thyroid 2016, 26, 1-133. [CrossRef]

22. Tuttle, R.M.; Fagin, J.A.; Minkowitz, G.; Wong, R.J.; Roman, B.; Patel, S.; Untch, B.; Ganly, I.; Shaha, A.R.; Shah, J.P. Natural history and tumor volume kinetics of papillary thyroid cancers during active surveillance. JAMA Otolaryngol. Head Neck Surg. 2017, 143, 1015-1020. [CrossRef]

23. Adam, M.A.; Pura, J.; Goffredo, P.; Dinan, M.A.; Hyslop, T.; Reed, S.D.; Scheri, R.P.; Roman, S.A.; Sosa, J.A. Impact of extent of surgery on survival for papillary thyroid cancer patients younger than 45 years. J. Clin. Endocrinol. Metab. 2015, 100, 115-121. [CrossRef] [PubMed] 
24. Lamartina, L.; Durante, C.; Lucisano, G.; Grani, G.; Bellantone, R.; Lombardi, C.P.; Pontecorvi, A.; Arvat, E.; Felicetti, F.; Zatelli, M.C. Are evidence-based guidelines reflected in clinical practice? An analysis of prospectively collected data of the Italian Thyroid Cancer Observatory. Thyroid 2017, 27, 1490-1497. [CrossRef] [PubMed]

25. Cabanillas, M.E.; McFadden, D.G.; Durante, C. Thyroid cancer. Lancet 2016, 388, 2783-2795. [CrossRef]

26. Ho, A.S.; Luu, M.; Barrios, L.; Chen, I.; Melany, M.; Ali, N.; Patio, C.; Chen, Y.; Bose, S.; Fan, X. Incidence and mortality risk spectrum across aggressive variants of papillary thyroid carcinoma. JAMA Oncol. 2020, 6, 706-713. [CrossRef] [PubMed]

27. Llamas-Olier, A.E.; Cuéllar, D.I.; Buitrago, G. Intermediate-risk papillary thyroid cancer: Risk factors for early recurrence in patients with excellent response to initial therapy. Thyroid 2018, 28, 1311-1317. [CrossRef] [PubMed]

28. Hess, K.R.; Levin, V.A. Getting more out of survival data by using the hazard function. Clin. Cancer Res. 2014, 20, 1404-1409. [CrossRef]

29. Hay, I.D.; Johnson, T.R.; Kaggal, S.; Reinalda, M.S.; Iniguez-Ariza, N.M.; Grant, C.S.; Pittock, S.T.; Thompson, G.B. Papillary thyroid carcinoma (PTC) in children and adults: Comparison of initial presentation and long-term postoperative outcome in 4432 patients consecutively treated at the Mayo Clinic during eight decades (1936-2015). World J. Surg. 2018, 42, 329-342. [CrossRef]

30. Schneider, D.F.; Mazeh, H.; Chen, H.; Sippel, R.S. Lymph node ratio predicts recurrence in papillary thyroid cancer. Oncologist 2013, 18, 157. [CrossRef]

31. Albasri, A.; Sawaf, Z.; Hussainy, A.S.; Alhujaily, A. Histopathological patterns of thyroid disease in Al-Madinah region of Saudi Arabia. Asian Pac. J. Cancer Prev. 2014, 15, 5565-5570. [CrossRef]

32. Raef, H.; Alfadhli, E.; Al-Hajjaj, A.; Malabu, U.H.; Al-Sobhi, S.; Rifai, A.; Al-Nuaim, A. High rate of persistent/recurrent disease among patients with differentiated thyroid cancer in Saudi Arabia: Factors affecting non-remission. Ann. Saudi Med. 2008, 28, 277-281. [CrossRef]

33. Gimbrone, M.A., Jr.; Leapman, S.B.; Cotran, R.S.; Folkman, J. Tumor dormancy in vivo by prevention of neovascularization. J. Exp. Med. 1972, 136, 261-276. [CrossRef] [PubMed]

34. Varani, J.; Lovett, E.J., III; Lundy, J. A model of tumor cell dormancy: Effects of anesthesia and surgery. J. Surg. Oncol. 1981, 17, 9-14. [CrossRef] [PubMed]

35. Demicheli, R.; Retsky, M.W.; Hrushesky, W.J.; Baum, M. Tumor dormancy and surgery-driven interruption of dormancy in breast cancer: Learning from failures. Nat. Clin. Pract. Oncol. 2007, 4, 699-710. [CrossRef]

36. Yin, W.; Di, G.; Zhou, L.; Lu, J.; Liu, G.; Wu, J.; Shen, K.; Han, Q.; Shen, Z.; Shao, Z. Time-varying pattern of recurrence risk for Chinese breast cancer patients. Breast Cancer Res. Treat. 2009, 114, 527-535. [CrossRef] [PubMed]

37. Feng, X.-Y.; Chen, Y.-B.; Wang, W.; Guan, Y.-X.; Li, Y.-F.; Chen, S.; Sun, X.-W.; Li, W.; Xu, D.-Z.; Zhan, Y.-Q. Time-varying pattern of recurrence risk for gastric cancer patients. Med Oncol. 2013, 30, 514. [CrossRef] [PubMed]

38. Zhu, J.-F.; Feng, X.-Y.; Zhang, X.-W.; Wen, Y.-S.; Lin, P.; Rong, T.-H.; Cai, L.; Zhang, L.-J. Time-varying pattern of postoperative recurrence risk of early-stage (T1a-T2bNOM0) non-small cell lung cancer (NSCLC): Results of a single-center study of 994 Chinese patients. PLoS ONE 2014, 9, e106668. [CrossRef] [PubMed]

39. Demicheli, R.; Valagussa, P.; Bonadonna, G. Double-peaked time distribution of mortality for breast cancer patients undergoing mastectomy. Breast Cancer Res. Treat. 2002, 75, 127-134. [CrossRef]

40. Wang, X.; Zhu, J.; Li, Z.; Wei, T. The benefits of radioactive iodine ablation for patients with intermediate-risk papillary thyroid cancer. PLOS ONE 2020, 15, e0234843. [CrossRef]

41. Kim, H.J.; Kim, N.K.; Choi, J.H.; Kim, S.W.; Jin, S.M.; Suh, S.; Bae, J.C.; Min, Y.K.; Chung, J.H.; Kim, S.W. Radioactive iodine ablation does not prevent recurrences in patients with papillary thyroid microcarcinoma. Clin. Endocrinol. 2013, 78, 614-620. [CrossRef]

42. Kim, S.K.; Woo, J.-W.; Lee, J.H.; Park, I.; Choe, J.-H.; Kim, J.-H.; Kim, J.S. Radioactive iodine ablation may not decrease the risk of recurrence in intermediate-risk papillary thyroid carcinoma. Endocr. Relat. Cancer 2016, 23, 367-376. [CrossRef]

43. Abubaker, J.; Jehan, Z.; Bavi, P.; Sultana, M.; Al-Harbi, S.; Ibrahim, M.; Al-Nuaim, A.; Ahmed, M.; Amin, T.; Al-Fehaily, M. Clinicopathological analysis of papillary thyroid cancer with PIK3CA alterations in a Middle Eastern population. J. Clin. Endocrinol. Metab. 2008, 93, 611-618. [CrossRef] [PubMed] 
44. Bu, R.; Siraj, A.K.; Al-Obaisi, K.A.; Beg, S.; Al Hazmi, M.; Ajarim, D.; Tulbah, A.; Al-Dayel, F.; Al-Kuraya, K.S. Identification of novel BRCA founder mutations in Middle Eastern breast cancer patients using capture and Sanger sequencing analysis. Int. J. Cancer 2016, 139, 1091-1097. [CrossRef] [PubMed]

Publisher's Note: MDPI stays neutral with regard to jurisdictional claims in published maps and institutional affiliations.

(C) 2020 by the authors. Licensee MDPI, Basel, Switzerland. This article is an open access article distributed under the terms and conditions of the Creative Commons Attribution (CC BY) license (http://creativecommons.org/licenses/by/4.0/). 